\title{
Sodium Fluoride does not Alter Sperm Production or Sperm Morphology in Rats
}

\author{
Lea Rosa Chioca*, Juliane Centeno Müller, Ana Cláudia Boareto, Roberto Andreatini and \\ Paulo Roberto Dalsenter \\ Departamento de Farmacologia; Universidade Federal do Paraná; Curitiba - PR - Brasil
}

\begin{abstract}
The aim of the present study was to evaluate the effects of sodium fluoride (NaF) on the male reproductive system. Adult male rats were exposed to NaF in drinking water for 30 days at three concentrations: 1.54 (control, tap water), 50 and 100 ppm. Body and organ weights, daily sperm production, sperm number and morphology were investigated. No difference was observed on the sperm number and morphology among the groups, as well as body weight and organ absolute and relative weights. Overall, despite the presence of a mild degree of dental fluorosis in the higher dose group, the results indicated that exposure to NaF at the doses used in the present study did not adversely affect sperm production and morphology of male rats.
\end{abstract}

Key words: Fluoride, sodium fluoride, male rats, reproductive toxicology, dental fluorosis, sperm

\section{INTRODUCTION}

Fluoride is a natural element present in the environment. It has been added to tap water in an effort to reduce the incidence of dental caries, but nowadays fluoride can be found in other sources such as food, beverages and dental products (Buzalaf et al. 2004). This can lead to a high ingestion of fluoride by the population, what may result in toxic effects (Whitford 1990; Spittle 1994).

Besides skeletal and dental fluorosis (Browne et al. 2005), chronic fluoride toxicity has been related to biological changes. Data suggest that excessive exposure to fluoride may be associated with central nervous system and reproductive dysfunctions in humans and other animals (Spittle 1994; Spittle 2008; Chioca et al. 2007).

Epidemiological studies have indicated lower levels of serum testosterone in men living in fluorosis endemic areas, exposed to 1.5 - $14.5 \mathrm{ppm}$ $\mathrm{F}$ in drinking water (Susheela and Jethanandani 1996) or when exposed to $3-27 \mathrm{mg}$ F/day occupationally (Ortiz-Périez et al. 2003).

Studies using laboratory animals focusing the effects of fluoride on reproductive functions show conflicting results. Studies have shown no impairment on spermatogenesis (Sprando et al. 1998) or adverse effect on reproduction in male rats treated with sodium fluoride $(\mathrm{NaF})$ (Collins et al. 2001). However, there are evidences that fluoride intake may cause diminished sperm and lower reproductive hormone levels, leading to a reduced fertility in male rats, receiving $\mathrm{NaF}$ (Chinoy et al. 1995; Izquierdo-Vega et al. 2008). Moreover, other effects like decline in sperm density and sperm viability, increase in sperm abnormalities, testicular histological alterations, were detected in male rats exposed to $150 \mathrm{ppm}$ $\mathrm{NaF}$ (Liu et al. 2008).

*Author for correspondence: leachioca@yahoo.com.br 
In a previous study, Chioca et al. (2007) reported memory impairment in rats treated with 50 and $100 \mathrm{ppm} \mathrm{NaF}$ in their drinking water for 30 days. This treatment also induced mild fluorosis in rat incisors. The aim of the present study was to evaluate whether this same fluoride treatment scheme could provoke alterations on the male reproductive system.

\section{MATERIALS AND METHODS}

\section{Animals}

Adult male Wistar rats, about 70 days old, weighing 280-350 g were housed alone in order to record individual food and water intake and maintained in controlled conditions at $22 \pm 2^{\circ} \mathrm{C}$ and $12 \mathrm{~h} \mathrm{light} / 12 \mathrm{~h}$ dark cycle. Food and water were available ad libitum. The experiments reported here were performed in accordance with the National Institute of Health Guide for the Care and Use of Laboratory Animals (USA), and were approved by the internal Ethics Committee for Animal Experimentation of the Federal University of Paraná State (protocol number 135).

\section{Fluoride administration}

The experimental groups (10 rats per group) received sodium fluoride solution containing 50 or $100 \mathrm{ppm} \mathrm{NaF}$. The control group received drinking water containing $1.54 \mathrm{ppm} \mathrm{NaF}$ (tap water, supplied by the State Water Company to the residents of Curitiba, Brazil). Animals were treated for 30 days.

\section{Food, water and $\mathrm{NaF}$ intake and body weight gain}

The food and water bottles were weighed every three days during the treatment in order to calculate the mean daily food, tap water or $\mathrm{NaF}$ solution intake per rat. The rats were weighed on day zero (baseline) and then $24 \mathrm{~h}$ after the last day of treatment (day 30). Body weight gain was calculated as the difference between the final and baseline weight.

\section{Dental fluorosis}

The degree of rat teeth fluorosis was evaluated in the incisors and assessed using the $0-5$ scoring method of Boulton et al. (1995) as described by Ekambaram and Paul (2003). Scoring was realized as follows: (0) normal shaped teeth and smooth, glossy orange-yellow enamel color; (1) slight whitening of the enamel; (2) faint horizontal banding of the enamel; chalky spots, slight erosion; (3) chalky enamel, moderate erosion of tips, staining; (4) pitting and chipped off edges, loss of enamel color and heavy staining; (5) cutting tips splayed and eroded to blunt stubby abnormal curvature.

\section{Body and organ weights}

The animals were killed by decapitation. The liver, kidneys, testis, epididymis, ventral prostate, and seminal vesicle were removed and weighed. The seminal vesicle was weighed without fluid. Organ weights were reported as absolute and relative weights (organ weight/body weight $x$ 100). In the case of kidneys, testis and epididymis, weights were presented as mean of both, left and right.

\section{Sperm evaluation}

After removing the tunica albuginea, both testis was minced and homogenized in $10 \mathrm{ml}$ of $0.9 \%$ $\mathrm{NaCl}$ containing $0.5 \%$ Triton $\mathrm{X}-100$ at medium speed in a POTTER $S^{\circledR}$ tissuemizer for $1 \mathrm{~min}$. After dilution, the number of homogenizationresistant spermatids was counted in a hemocytometer (Bürker, Germany). The number of homogenization resistant spermatids obtained by summing the scores of right and left testis, was divided by 6.1 , the number of days these spermatids were present in the seminiferous epithelium, to convert them to daily sperm production per testis (Robb et al. 1978). Daily sperm production per gram was calculated to determine the efficiency of the process (Ashby et al. 1997). The cauda epididymis (right and left) was cut into small pieces, homogenized, and spermatozoa were counted as described above. Also, the epididymal sperm transit rate was estimated for each male rat by dividing the epididymal sperm number by the daily sperm production (Amann 1982). To assess the percentage of morphologically abnormal sperm, the ductus deferens was rinsed with $0.5 \mathrm{ml} 0.9 \%$ $\mathrm{NaCl}$ to obtain a sperm suspension. Aliquots of the sperm suspension were stained with eosin. One hundred sperms per animal were analyzed microscopically at $400 \times$ magnification and sperm with abnormal heads and/or abnormal tails were scored (Robb et al. 1978).

\section{Statistical analysis}

Data were tested for the normal distribution and then analyzed by the analysis of variance 
(ANOVA), followed by the Newman-Keuls test (food and water intake) or Bonferroni Test (body and organ weights and sperm evaluation). Chisquare test was used to analyses the dental fluorosis. The level of significance was set at $p<$ 0.05 .

\section{RESULTS}

Food, water and sodium fluoride intake, body weight gain and fluorosis

No significant effect of fluoride on mean daily fluid and food consumption or body weight gain was observed (Table 1). Thus, as expected, the sodium fluoride intake increased proportionally to water fluoride concentration. A slight dental fluorosis was observed in the $100 \mathrm{ppm} \mathrm{NaF}$ treated rats, although no rat presented a degree of fluorosis greater than 1 (Table 1).

\section{Body and organ weights}

Body and organ weights (liver, kidneys, testis, epididymis, ventral prostate and seminal vesicle) did not differ from the control group (Table 2).

\section{Sperm evaluation}

Sperm number in the cauda epididymis, daily sperm production, daily sperm production per gram of testis, sperm transit rate and abnormal sperm (\%) did not differ from the control group (Table 3).

Table 1 - Mean daily fluid, food and sodium fluoride consumption, body weight gain and degree of dental fluorosis (incisors teeth) of rats treated with sodium fluoride.

\begin{tabular}{|c|c|c|c|c|c|c|}
\hline \multirow[t]{2}{*}{ Groups } & \multirow{2}{*}{$\begin{array}{c}\text { Daily fluid } \\
\text { consumption } \\
(\mathbf{m L})\end{array}$} & \multirow{2}{*}{$\begin{array}{c}\text { Daily food } \\
\text { consumption } \\
\text { (g) }\end{array}$} & \multirow{2}{*}{$\begin{array}{l}\text { Sodium } \\
\text { fluoride } \\
\text { (mg/kg) }\end{array}$} & \multirow{2}{*}{$\begin{array}{l}\text { Body weight } \\
\text { gain (g) }\end{array}$} & \multicolumn{2}{|c|}{$\begin{array}{c}\text { Degree of dental } \\
\text { fluorosis }\end{array}$} \\
\hline & & & & & 0 & 1 \\
\hline Control & $39.77 \pm 6.45$ & $24.25 \pm 1.23$ & $0.11 \pm 0.02$ & $80.50 \pm 24.16$ & 8 & 2 \\
\hline $50 \mathrm{ppm}$ & $37.77 \pm 4.05$ & $24.12 \pm 2.57$ & $5.18 \pm 0.69 *$ & $84.55 \pm 28.52$ & 3 & 6 \\
\hline $100 \mathrm{ppm}$ & $39.39 \pm 7.11$ & $23.71 \pm 2.21$ & $11.02 \pm 1.87^{* \dagger}$ & $81.80 \pm 26.58$ & $2 *$ & $8 *$ \\
\hline
\end{tabular}

Data represents mean $\pm \mathrm{SD} ; \mathrm{n}=10$ rats/ group (for dental fluorosis: data represents frequency of 9 rats/group for $50 \mathrm{ppm}$ and 10rats/group for 1.54 and $100 \mathrm{ppm})$.

$* \mathrm{p}<0.05$ compared to $1.54 \mathrm{ppm}$.

${ }^{\dagger} \mathrm{p}<0.05$ compared to $50 \mathrm{ppm}$.

Table 2 - Body weight and absolute and relative organ weight of male rats treated with sodium fluoride.

\begin{tabular}{llllllc}
\hline & \multicolumn{3}{c}{ Absolute weight (g) } & \multicolumn{3}{c}{ Relative weight (\%) } \\
\cline { 2 - 7 } & Control & $\mathbf{5 0} \mathbf{~ p p m}$ & $\mathbf{1 0 0} \mathbf{~ p p m}$ & Control & $\mathbf{5 0} \mathbf{~ p p m}$ & $\mathbf{1 0 0} \mathbf{~ p p m}$ \\
\hline Body & $368 \pm 7.4$ & $365 \pm 9.04$ & $362 \pm 10.3$ & & & \\
Liver & $13.02 \pm 0.81$ & $13.38 \pm 0.85$ & $13.05 \pm 1.60$ & $3.54 \pm 0.14$ & $3.67 \pm 0.24$ & $3.60 \pm 0.24$ \\
Kidneys & $1.07 \pm 0.05$ & $1.07 \pm 0.08$ & $1.09 \pm 0.10$ & $0.29 \pm 0.01$ & $0.29 \pm 0.01$ & $0.30 \pm 0.02$ \\
Testis & $1.69 \pm 0.14$ & $1.74 \pm 0.13$ & $1.72 \pm 0.11$ & $0.46 \pm 0.03$ & $0.48 \pm 0.04$ & $0.48 \pm 0.05$ \\
Epididymis & $0.55 \pm 0.06$ & $0.56 \pm 0.03$ & $0.53 \pm 0.05$ & $0.15 \pm 0.01$ & $0.15 \pm 0.01$ & $0.14 \pm 0.01$ \\
Prostate & $0.42 \pm 0.15$ & $0.34 \pm 0.05$ & $0.36 \pm 0.10$ & $0.11 \pm 0.04$ & $0.09 \pm 0.01$ & $0.10 \pm 0.03$ \\
Seminal Vesicle & $0.50 \pm 0.05$ & $0.52 \pm 0.08$ & $0.49 \pm 0.08$ & $0.13 \pm 0.01$ & $0.14 \pm 0.02$ & $0.13 \pm 0.02$ \\
\hline
\end{tabular}

Data represents mean $\pm \mathrm{SD} ; \mathrm{n}=10$ rats/ group.

Table 3 - Sperm number in the cauda epididymis, daily sperm production, daily sperm production per gram of testis, sperm transit rate and abnormal sperm (\%) of male rats treated with sodium fluoride.

\begin{tabular}{|c|c|c|c|c|c|}
\hline Groups & $\begin{array}{c}\text { Sperm number } \\
\left(\begin{array}{c}1^{6} \text { epididymis }^{-1} \\
\left.\text { day }^{-1}\right)\end{array}\right. \\
\end{array}$ & $\begin{array}{c}\text { Daily sperm } \\
\text { production } \\
\left(\times \mathbf{1 0}^{6} \text { testis }^{-1} \text { day }^{-1}\right) \\
\end{array}$ & $\begin{array}{c}\text { Daily sperm } \\
\text { production } \\
\text { (x gram of testis) } \\
\end{array}$ & $\begin{array}{c}\text { Sperm } \\
\text { transit rate } \\
\text { (days) } \\
\end{array}$ & $\begin{array}{c}\text { Abnormal } \\
\text { sperm } \\
(\%) \\
\end{array}$ \\
\hline Control & $756.1 \pm 69.2$ & $65.93 \pm 10.41$ & $39.89 \pm 5.93$ & $13.34 \pm 1.82$ & $8.90 \pm 1.58$ \\
\hline $50 \mathrm{ppm}$ & $686.2 \pm 97.3$ & $49.66 \pm 5.24$ & $28.6 \pm 3.06$ & $13.9 \pm 1.52$ & $7.83 \pm 1.27$ \\
\hline 100 ppm & $693.3 \pm 87.9$ & $50.05 \pm 6.33$ & $29.03 \pm 3.53$ & $14.13 \pm 0.91$ & $7.90 \pm 1.39$ \\
\hline
\end{tabular}

Data represents mean $\pm \mathrm{SD} ; \mathrm{n}=10$ rats/ group. 


\section{DISCUSSION}

The aim of this study was to evaluate whether sodium fluoride exposure at concentrations that caused memory impairment and dental fluorosis in the rats would cause impairment on the male reproductive function. The findings did not show impairment in the reproductive parameters evaluated. These results were in agreement with Sprando et al. (1998) who found no adverse effect on spermatogenesis in male rats receiving 25 to 250 ppm NaF after a 14-week treatment. Similarly, Collins et al. (2001) showed that $\mathrm{NaF}$ in the drinking water at levels up to $250 \mathrm{ppm}(28.4 \mathrm{mg}$ $\mathrm{NaF} / \mathrm{kg} /$ day) produced no adverse effect on the reproduction in rats and no cumulative effects were observed in three generations. However, that was not the case in the studies published by Gupta et al. (2007) in which exposure to $\mathrm{NaF}(2,4$ and 6 $\mathrm{ppm}$ in the drinking water) to adult rats for six months caused decrease in the mass of sexual organs, the number of primary and secondary spermatocytes, spermatids, as well as the number of Sertoli and Leydig cells and their areas.

Similarly, Izquierdo-Veja et al. (2008) reported reduced fertility in male rats receiving $5.0 \mathrm{mg}$ $\mathrm{F} / \mathrm{kg} /$ day. Huang et al. (2007) observed changes on cell cycle and cell apoptosis in mice testis with 200 and $300 \mathrm{mg} \mathrm{NaF} / \mathrm{L}$ in the drinking water, both having an exposure regime to $\mathrm{NaF}$ of 8 weeks.

To evaluate these contradictory results, in addition to the methodology used, it is important to consider the route and site of exposure, along with its duration and frequency (Eaton and Klassen 2001, Reddy et al. 2007). Also, the fluoride toxicity on reproductive system may be related with the period of treatment, such as prenatal or pubertal exposures. For example, Bera et al. (2007) observed sexual behavior impairment in descendants male rats exposed to $\mathrm{NaF}$ at a dose of 2.5 and $5.0 \mathrm{mg} / \mathrm{kg}$ during the critical periods of pregnancy and lactation.

Present results showed no change in average daily intake of fluid and food or body weight gain among the groups, indicating that the level of $\mathrm{NaF}$ used caused no alteration in water palatability or anorexia (U.S. EPA 1996). These results were in agreement with Collins et al. (2001), who observed adverse effects on the water consumption and body weight gain only when $\mathrm{NaF}$ levels higher than $100 \mathrm{ppm}$ were administered. In contrast, Chinoy et al. (1992) observed a reduction in body weight and sperm motility after $10 \mathrm{mg} / \mathrm{kg} /$ day $\mathrm{NaF}$ administration for 30 days to adult male rats. However, in this case, the sperm changes found might have occurred due to loss of rats' body weight.

Despite no change in body weight gain, the incisor teeth of rats receiving the $100 \mathrm{ppm} \mathrm{NaF}$ concentration became slightly whitened, suggesting a mild degree of fluorosis (Browne et al. 2005, Chioca et al. 2007). Calcified tissues such as bone and teeth are the main target of fluoride accumulation (NRC, National Research Council 2006). Thus, although $\mathrm{NaF}$ had no significant effect on water consumption and body weight gain, this exposure produced toxicity in dental tissue, which was the first visible sign of chronic fluoride intoxication (Browne et al. 2005). Moreover, this treatment schedule induced behavioral changes such as memory impairment (Chioca et al. 2007). Taken together, these results indicated that the doses used were able to induce toxicity.

Absolute and relative organ weight observed after the treatment indicated that there was no impairment in the reproductive organs function. Similarly, Collins et al. (2001) did not observe any change in the relative organ weight even with 250 ppm NaF concentration. In, contrast Ghosh et al. (2002) and Bataineh and Irbid (2006) showed a reduction in the reproductive organs weight without alteration in the body weight gain after $\mathrm{NaF}$ treatment. However, as significant changes in other important endpoints that are related to reproductive function may not be reflected in organ weight data, this information should serve to provide a basis for obtaining additional information on the reproduction toxicity, such as histological and hormonal analysis (U.S. EPA 1996). In this context, Chinoy and Sequeira (1989), by histological and hystocitometry analysis of reproductive organs, observed histoarchitecture changes in the seminiferous tubules, epididymis and vas deferens of male rats exposed to 30 days of treatment with 10 and 20 $\mathrm{mg} / \mathrm{kg}$ of NaF. However, withdrawal of treatment caused recovery in the histoarchitecture of these organs. Wan et al. (2006) observed histological changes in testicular tissues, decline in sperm viability and increase in sperm abnormalities up to 120 days after administration of $150 \mathrm{mg} \mathrm{NaF/L}$.

Although the epididymal sperm reserves, daily sperm production and sperm morphology were not altered after exposure to $\mathrm{NaF}$, it would be important to emphasize that exposure of rats to 
$\mathrm{NaF}$ was 30 days. This implied that if there was a change in the early stages of spermatogenesis, as the differentiation of stem A spermatogonium to primary spermatocytes, would not be possible to observe them, since the complete process of spermatogenesis occurs within an interval of 58 days (Amann 1982). Thus, these results indicated that exposure to NaF probably did not alter later stages of spermatogenesis. However, it would be important to evaluate the testicular histology for a more detailed investigation. Moreover, the transmissible germ-cell mutations might exist in the absence of any warning morphological indicator such as abnormal sperm (de Boer et al. 1976). Izquierdo-Vega et al. (2008) reported an increase in the oxidative stress and loss of mitochondrial transmembrane potential in spermatozoa of male rats receiving $\mathrm{NaF}$ doses similar to the ones used in the present study, which could lead to reduced fertility but not morphological changes.

It is important to correlate fluoride doses and serum fluoride levels in animal experiments with the real levels of exposure of different populations (Spittle 2008). The concentration of NaF which the rats were exposed to in the present study was higher than the concentration that humans have been usually exposed to. However, human beings have contact with fluoride for their entire lives, while in this study the animals received fluoride only for a short period of life. Thus, apparently the $100 \mathrm{ppm}$ fluoride induced fluoride serum concentration in the rats similar to the serum levels in humans with the intake 5-10 ppm fluoride (Smith et al. 1993). Consistent with this, the rats exposed to $100 \mathrm{ppm} \mathrm{NaF}$ showed mild fluorosis only. Moreover, because humans are exposed to multiple sources of fluoride, it is difficult to determine the real daily fluoride consumption.

In conclusion, the same fluoride treatment scheme that caused memory impairment and dental fluorosis in rats (Chioca et al. 2007) was not able to demonstrate alterations on average daily intake of fluid and food, body weight gain, absolute and relative organ weight, sperm number, daily sperm production, or number of abnormal sperm.

\section{ACKNOWLEDGEMENTS}

The authors are grateful to Aedra Bufalo and Giuliana G.K. Botelho who collaborated with some experiments. This research was partially supported by Fundação Araucária, CNPqConselho Nacional de Desenvolvimento Científico e Tecnológico and CAPES-Coordenação de Aperfeiçoamento de Pessoal de Nível Superior.

\section{REFERENCES}

Amann RP. Use of animal models for detecting specific alterations in reproduction. Fundam Appl Pharmacol. 1982; 2 (82), 13-25.

Ashby J, Lefevre PA, Odum J, Tinwell H, Kennedy SJ, Beresford N, Sumpter JP. Failure to confirm estrogenic activity for benzoic acid and clofibrate: implication for lists of endocrine-disrupting chemicals. Regul Toxicol Pharmacol. 1997; 26, 96101.

Bataineh HN, Irbid MKN. Impact of 12-week ingestion of sodium fluoride on aggression, sexual behavior, and fertility in adult male rats. Fluoride. 2006; 39, 293-301.

Bera I, Sabatini R, Auteri P, Flace P, Sisto G, Montagnani $M$, et al. Neurofunctional effects of developmental sodium fluoride exposure in rats. Eur Rev Med Pharmacol Sci. 2007; 11: 211-24.

Boulton IC, Cooke JA, Johnson MS. Fluoride accumulation and toxicity in laboratory populations of wild small mammals and white mice. J Appl Toxico. 1995; 15: 423-31.

Browne D, Whelton H, O'Mullane D. Fluoride metabolism and fluorosis. J Dent. 2005; 33: 177-86

Buzalaf MA, de Almeida, BS, Cardoso VE, Ollympio KP, Furlani T. Total and acid soluble fluoride content of infant cereals, beverages and biscuits from Brazil. Food Addit Contam. 2004; 21: 210-5.

Chinoy NJ, Sequeira E. Effects of fluoride on the histoarchitecture of reproductive organs of the male mouse. Reprod Toxicol. 1989; 4: 261-7.

Chinoy NJ, Pradeep PK, Sequeira E. Effects of fluoride ingestion on the physiology of reproductive organs of male rat. J Environ Biol. 1992; 13: 55-61.

Chinoy NF, Narayana MV, Dalal V, Rawat M, Patel D. Amelioration of fluoride toxicity in some accessory reproductive glands and spermatozoa of rat. Fluoride. 1995; 28: 75-86.

Chioca LR, Raupp IM, da Cunha C, Losso EM, Andreatini R. Subchronic fluoride intake induces impairment in habituation and active avoidance tasks in rats. Eur J Pharmacol. 2008; 579: 196-201.

Collins TF, Sprando RL, Black TN, Shackelford ME, Bryant MA, Olejnik N, Ames MJ, Rorie JI, Ruggles DI. Multigenerational evaluation of sodium fluoride in rats. Food Chem Toxicol. 2001; 39: 601-13. 
de Boer P, van der Hoeven FA, Chardon JA. The production, morphology, karyotypes and transporto $f$ spermatozoa from tertiary trisomic mice and the consequences for egg fertilization. J Reprod Fertil. 1976; 48: 249-56.

Eaton DL, Klaassen CD. Principles of Toxicology. In: Casarett LJ, Doll J, editors. The Basic Science of Poison. New York: Mc Graw-Hill; 2001. p. 11-33.

Ekambaram P, Paul V. Effect of vitamin D on chronic behavioral and dental toxicities of sodium fluoride in rats. Fluoride. 2003; 36: 189-97.

Elbetieha A, Darmani H, Irbid ASA. Fertility effects of sodium fluoride in male mice. Fluoride. 2000; 33: 128-34.

Ghosh D, Das Sarkar S, Maiti R, Jana D, Das UB. Testicular toxicity in sodium fluoride treated rats: association with oxidative stress. Reprod Toxicol. 2002; 16: 385-90.

Gupta RS, Khan TI, Agrawal D, Kachhawa JB. The toxic effects of sodium fluoride on the reproductive system of male rats. Toxicol Ind Health. 2007; 23(9): 507-13.

Huang C, Niu RY, Wang JD. Toxic effects of sodium fluoride on reproductive function in male mice. Fluoride. 2007; 40: 162-8.

Izquierdo-Vega JA, Sánchez-Gutiérrez M, Del Razo LM. Decreased in vitro fertility in male rats exposed to fluoride-induced oxidative stress damage and mitochondrial transmembrane potential loss. Toxicol Appl Pharmacol. 2008; 230: 352-7.

Liu H, Niu R, Wang J, He Y, Wang J. Changes caused by $\mathrm{F}$ and $\mathrm{Pb}$ in energy metabolic enzyme activities in the reproductive system of male offspring rats. Fluoride. 2008; 4: 184-91.

NRC (National Research Council). Fluoride in Drinking-Water. A Scientific Review of EPA's Standard. National Academy Press, Washington, DC. 2006.
Ortiz-Pérez D, Rodríguez-Martínez M, Martínez F, Borja-Aburto VH, Castelo J, Grimaldo JI, et al. Fluoride-induced disruption of reproductive hormones in men. Environ Res. 2003; 93: 20-30.

Robb GW, Amann RP, Killian GJ. Daily sperm production and epididymal sperm reverses of pubertal and adult rats. J Reprod Fertil. 1978; 54: 103-7.

Smith CE, Nanci A, DenBesten PK. Effects of chronic fluoride exposure on morphometric parameters defining the stages of amelogenesis and ameloblast modulation in rat incisors. Anat Rec. 1993; 237: 24358.

Spittle B. Psycopharmacology of fluoride: a review. Int Clin Psychopharmacol. 1994; 9: 79-82.

Spittle B. Fluoride and fertility. Fluoride. 2008; 4: 98100.

Sprando RL, Collins TFX, Black T, Olejnik N, Rorie J. Testing the Potential of Sodium Fluoride to Affect Spermatogenesis: a Morphometric Study. Food Chem Toxicol.1998; 36: 1117-24.

Susheela AK, Jethanandani P. Circulating testosterone levels in skeletal fluorosis patients. J Toxicol Clin Toxicol.1996; 34: 183-7.

U.S. EPA (Environmental Protection Agency). Guidelines for reproductive toxicity risk assessment. EPA/630/R-96/009,Washington, DC. 1996.

Wan S, Zhang J, Wang J. Effects of high fluoride on sperm quality and testicular histology in male rats. Fluoride. 2006; 39: 17-21.

Whitford GM. The physiological and toxicological characteristics of fluoride. J Dent Res. 1990; 69: 53949.

Received: October 06, 2009; Revised: August 18, 2010; Accepted: December 14, 2011 